\title{
ACCOUNTING FOR PURCHASED SOFTWARE BASED ON TURKISH ACCOUNTING STANDARDS
}

\section{DOI: 10.17261/Pressacademnia.2015211511}

\section{Recep Yilmaz', Ilker Calayoglu}

1Sakarya University. rcyilmaz@sakarya.edu.tr

²Okan University. ilkercalayoglu@outlook.com

\section{Keywords}

Software, useful life, research, development, revaluation.

\section{JEL Classification} M15, M41

\begin{abstract}
The first accounting record is made via determination of added and non-added costs of software purchased. Then amortization transaction must be accounted with respect to software useful life is limited or unlimited. Amortization cannot be done if the useful life of software is unlimited. In this article, it will be explained determination of useful life of software is limited or unlimited with the examples based on IAS 38. Before amortization of software purchased, it must be examine whether it is using in production period or not. Usage of software in production period is development activity and it have to be capitalize and other activities have to be expensed. Depreciation is recorded accordingly. In this article it is explained reasons of almost none revaluation. It is also explained that if revaluation is necessary, how it can be done. New account names are proposed because account names are not appropriate for concept of Turkish accounting standards.
\end{abstract}

\section{SATIN ALINAN YAZILIMLARIN TÜRKIYE MUHASEBE STANDARTLARINA GÖRE MUHASEBELEŞTiRILMESi ${ }^{1}$}

\section{Anahtar Kelimeler \\ Yazılım, faydalı ömür, araştırma, geliştirme, yeniden değerleme.}

JEL Sınıflandırması M15, M4

\section{ÖZET}

Satın alınan yazılımın maliyetine eklenecek ve eklenemeyecek harcamaların tespiti ile ilk muhasebeleştirme işlemi gerçekleştirilir. Daha sonra yazılımın faydalı ömrünün sınırlı mı sınırsız mı olduğuna göre itfa payı hesaplanmalıdır. Faydalı ömrün sınırsız olduğu durumlarda itfa payı ayrılmaz. Bunun tespitine dair TMS 38 standardı yorumlanmış ve uygulamadan örneklerle açıklanmaya çalışıımıştır. Satın alınan yazılımın itfası kayıt edilmeden önce üretim işlemlerinde kullanılıp kullanılmadığının incelenmesi gerekmektedir. Üretim işlemlerindeki kullanımlar geliştirme faaliyetidir ve aktifleştirilmelidir. Üretim haricindeki kullanımlar giderleştirilir. Amortisman kaydı da buna uygun şekilde kaydedilir. Yeniden değerleme konusunda neden neredeyse hiç hesaplama yapılamayacağı sebepleriyle açıklanmıştır. Değerleme yapılması gerektiğinde nasıl yapılacağı da açıklanmıştır. Tek düzen hesap planı ile Türkiye Muhasebe Standartlarının uyumu açısından konuyla ilgili bazı hesap isimleri de önerilmiştir.

1 Bu çalışma yazarların ICEB 2015'te sunmak üzere kabul aldıkları bildirinin gözdenden geçirilmiş halidir. 


\section{GiRiş}

Yazılım, bir teknoloji ve bilişim terimidir. Yazııı, çalıştırıldığında bilgisayara belli fonksiyonları yaptırabilen bir dizi komutlar bütünüdür. (Tavukçuoğlu, 2004) Tanım dâhilinde geçen komut kavramı ise bilgisayara, klavye veya diğer giriş birimlerinden, bir takım işler yaptırabilmek amacıyla verilen emirler anlamına gelmektedir. (Arpacı, 2010:4) Yazılım kavramı, ilk kez istatistikçi John Wilder Tukey tarafından 1958 yılında "American Mathematics Monthly" dergisinde yayınlanan bir makalede elektronik hesaplamalarda kullanılan programları tanımlamak amacıyla kullanmıştır. (Britannica, 2014)

Yazılımın kendisini fiziki olarak görmemiz ve dokunmamız mümkün değildir, çünkü yazılımlar bilgisayarın belleğine yüklenen komutlardan ibarettir. Sadece yazılımın kodları görülebilir ve değiştirilebilir. Yazılımı olmayan bir bilgisayar çalıştırıldığında ekranda sadece boş bir görüntü oluşur. Kısacası yazılımlar hep bir ihtiyacı gidermek için oluşturulan, tekrar tekrar aynı sorguyu veya işlemi yapmaktan bıkmayan, donanımların kullanılmasına da imkân veren komutlar bütünüdür.

Türk Dil Kurumunun sözlüğüne göre yazılım; bir bilgi işlem dizgesinin işleyişi ile ilgili bilgisayar izlencelerinin, yordamların, kuralların ve gerektiğinde belgelemenin tümü şeklinde tanımlanmaktadır. (TDK, 1981) Buna göre yazılım; belirli bir işlev odaklı olan ancak soyut özelliklere sahip bir varlıktır.

Yazılımın tanımı ve özelliklerinden de anlaşılacağı üzere işletmeler kendi iş süreçlerini daha iyi yönetebilmek için kendi ihtiyaçlarına cevap verebilen yazılımları satın alırlar. Bu yazılımları üretim, pazarlama, muhasebe ve vb. gibi iş süreçlerinde kullanırlar.

Bu çalışmanın amacı, satın alınan yazılımların hangi durumlarda nasıl muhasebeleşmesi gerektiğine açıklık getirmektir. TMS 38 standardı kapsamında genel hükümler bulunmaktadır. Ancak literatürdeki yetersiz kaynağa katkı yapmak istendiğinden örnek işlemler ile konu açıklanmıştır. Çalışma beş bölümden oluşmaktadır. illk bölümde, TMS 38 Standardındaki tanımlamalar ortaya konmuştur. İkinci bölümde, yazılımın satın alınmasında maliyet olarak kabul edilen kalemler açıklanmıştır. Üçüncü bölümde, satın alınan yazılımın ilk muhasebe kaydı örnekler ile açıklanmıştır. Dördüncü bölümde, yazılımın faydalı ömrü ve amortisman ilişkisi açıklanmıştır. Beşinci bölümde ise yeniden değerleme konusunda önce görüş bildirilmiş, ardından gerektiğinde hesaplamaların nasıl yapılması gerektiği açıklanmıştır.

\section{TMS 38 STANDARDINDAKI TANIMLAMALAR}

38 numaralı Türkiye Muhasebe Standartları kapsamında maddi olmayan kalemler ve varlık adında iki kavramdan bahsedilmektedir. Öncelikle yazılımların bu standarda göre değerlendirilip değerlendirilmeyeceğine dair bazı tanımlamaları ve özellikleri incelemek gerekir. Standarda göre Maddi OImayan Kalemler ve Maddi Olmayan Varlıklar şunlardır;

a) Maddi Olmayan Kalemler: "İşletmeler sıklıkla kaynak tüketir veya bilimsel ya da teknik bilgi, yeni süreç veya sistemlerin tasarım ve uygulanması, lisans, fikri mülkiyet hakları, piyasa bilgisi ve markalar (marka isimleri ve yayın hakları dâhil) gibi maddi olmayan kaynakların elde etme, geliştirme, bakım veya iyileştirilmesi sırasında çeşitli borçlar yüklenirler. Bu geniş kapsamlı başlıklar altındaki kalemlerin yaygın örnekleri; bilgisayar yazılımı, patentler, telif hakları, sinema 
filmleri, müşteri listeleri, ipotek hizmeti sunma hakları, balıkçılık lisansları, ithalat kotaları, isim hakları, müşteri ve tedarikçi ilişkileri, müşteri sadakati, pazar payı ve pazarlama haklarıdır." (TMS-38, Türkiye Muhasebe Standartları, 9)

"Yukarıda tanımlanan bütün kalemler, bir maddi olmayan duran varlık, örneğin belirlenebilirlik, bir kaynak üzerindeki kontrol ve gelecekteki ekonomik yararının varlığı gibi, tanımını karşılamaz." (TMS-38, 10)

Bu durumda maddi olmayan kalemler içinde sayılmış olan bilgisayar yazılımlarının TMS 38 'in belirlenebilirlik, kontrol ve gelecekteki ekonomik yararların varlığı şartlarını da sağlamalıdır.

b) Maddi Olmayan Varlık: Maddi olmayan kalemler arasında sayılan varlıkların, belirlenebilirlik, kontrol ve gelecekteki ekonomik yararların varlığı şartlarını sağlayanlardır. Bu şartlar şu şekilde açıklanmıştır.

- Belirlenebilirlik şartı: Maddi olmayan duran varlıklar şerefiyeden ayrılabilir olmalıdır. Bunun için ayrı bir şekilde ölçülebilir ve raporlanabilir olmalıdır ki şerefiyeden ayrılabilir olsun. Bu manada ....satılabilir, devredilebilir, lisans altına alınabilir, kiralanabilir ya da takas edilebilir olmalıdır. (TMS-38, 12)

- Kontrol şartı: “iş̧letmenin ilgili varlıktan ortaya çıkan gelecekteki ekonomik yararları kullanabilme ve başkalarının bu yararlara erişimini kısıtlama gücü olması durumunda, bu varlıktan ekonomik yarar sağlama gücü var demektir." (TMS-38, 13)

- Gelecekteki ekonomik yararlar şartı: “Maddi olmayan duran varlıktan beklenilen gelecekteki ekonomik yararlar; ürün ve hizmet satışından sağlanan geliri, maliyet tasarruflarını ya da işletme tarafından varlıkların kullanımından kaynaklanan diğer yararları içerebilir." (TMS-38, 17)

"Normalde, işletmenin bir maddi olmayan duran varlığı ayrı olarak elde etmek için ödemiş olduğu fiyat, varlıktan beklenilen gelecekteki ekonomik yararların işletme tarafından elde edilme olasılığı ile ilgili işletmenin beklentilerini yansıtır. Diğer bir deyişle, işletme fayda akışının zamanlamasında ve tutarında belirsizlik olsa bile ekonomik fayda akışının olmasını beklemektedir. Bu nedenle Paragraf 21(a)'daki olasılıkla ilgili muhasebeleştirme kriteri, ayrı olarak elde edilen maddi olmayan duran varlıklar açısından her zaman için sağlanmış kabul edilir. Ek olarak, ayrı olarak elde edilen bir maddi olmayan duran varlığın maliyeti, genellikle güvenilir bir şekilde ölçülebilir. Bu, özellikle, satın alma bedelinin nakit veya diğer parasal varlıklarla ödenmiş olması durumunda geçerlidir." (TMS-38, 25-26)

Yukarıdaki kriterler incelendiğinde satın alınan yazılımlar gelecekteki ekonomik yarar şartını sağlamaktadır. Zaten satın almanın amacında böyle bir beklenti vardır. İşletme satın aldığı yazılım üzerinde kontrol gücüne sahiptir, çünkü yazılımın kullanılmasını istediği zaman başlatabilir veya istediği zaman durdurabilir. Bu şekilde irade edilebilir olduğunda da işletme şerefiyesinden ayrı olarak kaydetmek, izlemek ve raporlamak mümkündür. $O$ halde satın alınan yazılımlar TMS 38 kapsamınca maddi olmayan duran varlık olarak kabul edilmekte ve standardın hükümlerince muhasebeleştirilebilecektir. 


\section{YAZILIMIN SATIN ALINMASI VE MALIYETLER}

Yazılım satın alınması işleminde işletmeye tedarik edilen varlık soyuttur. Fiziksel bir unsur yoktur. Ancak tedarik edilen nesnenin işlevsel ve fayda sağlayan özellikleri vardır. Bu faydalardan yararlanabilmek için söz konusu yazııım, işletme bilgisayarlarına kurulmalıdır. Böylece işletme söz konusu yazılımdan faydalanmaya başlayabilir. Ancak yazılımın tam işlevselliği belirli bir süre ile sınırlıdır. Satın alma sözleşmesinde yazılım lisansının geçerlilik süresi muhakkak vardır. Bu durum yazılımdan faydalanmaya bir sınır getirmektedir. Yani, satın alınan unsur yazılımın kullanım hakkıdır.

Bir yazılımın satın alma fiyatı işletmenin elde etme maliyetini oluşturur. Buna ilave olarak eklenebilecek bazı harcamalar daha olabilir. Bunlar şunlardır; (TMS-38, 27-28)

1. İthalat vergileri ve iade edilmeleri mümkün olmayan satın alma vergileri de dâhil, ticari ıskontolar ve indirimler düşüldükten sonraki satın alma fiyatı ve

2. Varlığı, amaçlanan kullanımına hazır hale getirmeye yönelik, doğrudan varlıkla ilişkilendirilebilen herhangi bir maliyet.

Varlıkla doğrudan ilişkilendirilebilen maliyetlere ilişkin örneklere aşağıda yer verilmiştir:

1. Doğrudan, varlığın çalışabilir duruma getirilmesi sırasında oluşan ("TMS 19 Çalışanlara Sağlanan Faydalar" Standardında tanımlandığı gibi) çalışanlara sağlanan fayda maliyetleri;

2. Doğrudan, varlığın çalışabilir duruma getirilmesi sırasında oluşan mesleki ücretler ve

3. Varlığın düzgün çalışıp çalışmadığının testine yönelik maliyetler.

Bu duruma göre yazılımın çalışır hale gelinceye kadar yapılan işlerden direkt ilişkili olan işlemler için yapılan harcamalar da yazılımın maliyetine eklenmelidir.

\section{4. İLK MUHASEBELEŞTiRME}

Yazılımlar Tek Düzen Hesap Planı 260 Haklar hesabında izlenmelidir. Bu hesabın tanımına göre "Imtiyaz, patent, lisans, ticari marka ve unvan gibi bir bedel ödenerek elde edilen bazı hukuki tasarruflar ile kamu otoritelerinin işletmeye belirli alanlarda tanıdığı kullanma, yararlanma gibi yetkiler dolayısıyla yapılan harcamaları kapsar." işleyişine göre "Edinilen haklar, maliyet bedelleri ile bu hesaba borç kaydedilir. Yararlanma süreleri içerisinde, yararlanma sürelerinin belli olmaması durumunda, 5 yıllık sürede eşit taksitlerle itfa olunarak yok edilir." (GiB, 2015)

Buna göre ilk muhasebeleştirme ve sonrasında alınabilecek kararlar ve yapılabilecek harcamaların nasıl muhasebeleşmesi gerektiğine dair birbiri ile ilişkili aşağıdaki örnekleri dikkatle incelemek gerekir.

Örnek 1; Ahmet A.Ş. işletmesinde geliştireceği yazılımlar için bir alt yapı oluşturmaktadır. Bu kapsamda birden fazla yazılım 1 yıllık süre ile 5 kişilik kullanım hakkı için sözleşmeler yapılmış ve satın alınmıştır. Satın alınma tarihi 01.01.2015'tir. Yazılımlar şunlardır: 
Tablo 1: Satın Alınan Yazılımların Listesi ve Fiyatları

\begin{tabular}{|l|l|c|}
\hline No & Yazılım İsmi & Fiyatı \\
\hline $\mathbf{1}$ & Visual Studio 2013 & $3.000 \mathrm{TL}$ \\
\hline $\mathbf{2}$ & MS SQL Server Standard Edition 2012 & $7.500 \mathrm{TL}$ \\
\hline $\mathbf{3}$ & Crystal Report & $1.500 \mathrm{TL}$ \\
\hline $\mathbf{4}$ & MS Team foundation server & $7.500 \mathrm{TL}$ \\
\hline
\end{tabular}

Daha sonra işletmede kurulması ve işler olabilmesi amacıyla 4 numaralı varlık için $1.500 \mathrm{TL}$ kurulum ücreti ve kurulum ile test aşamasında geçen süre için de servis sağlayıcının çalışanına 1.000 TL ödemiştir. Aşağıdaki gibi muhasebeleşmesi gerekmektedir.

Tablo 2: Örnek 1'in Muhasebe Kaydı

\begin{tabular}{|l|r|r|}
\hline \multicolumn{1}{|c|}{ Hesap Adı } & Borç & Alacak \\
\hline $\mathbf{2 6 0}$ Haklar & $\mathbf{2 2 . 0 0 0}$ & \\
\hline 260.01 Visual Studio 2013 & 3.000 & \\
\hline 260.02 MS SQL Server Standard Edition 2012 & 7.500 & \\
\hline 260.03 Crystal Report & 1.500 & \\
\hline 260.04 MS Team foundation server (7.500+1.500+1.000) & 10.000 & \\
\hline 100 Kasa Hesabı & & $\mathbf{2 2 . 0 0 0}$ \\
\hline
\end{tabular}

Illk kurulum için yapılan harcamalardan kurulum ücreti, kurulumda ve test süreçlerinde çalışan görevli çalışana ödenen ücretler, yazılımın işler olabilmesi için yapıldığından elde etme harcamaları kapsamındadır ve varlığın maliyetine eklenir. 4 numaralı varlık için de böyle olmuştur. (Sumer ve Erer, 2010:37)

Örnek 2; aynı varlık için 1 yıllık bakım ve danışmanlık sözleşmesi yapılmıştır. Bedeli 2.400 TL'dir.

Tablo 3: Örnek 2'nin Muhasebe Kaydı

\begin{tabular}{|c|c|c|}
\hline Hesap Adı & Borç & Alacak \\
\hline 180 Gelecek Aylara Ait Giderler & 2.400 & \\
\hline 180.01 MS Team Foundation Server 1 Yıllık Bakımı & 2.400 & \\
\hline 100 Kasa Hesabı & & 2.400 \\
\hline 770 Genel Yönetim Giderleri & 200 & \\
\hline 770.05 MS Team Foundation Server Bakım Gideri $(2.400 / 12=200)$ & 200 & \\
\hline 180. Gelecek Aylara Ait Giderler & & 200 \\
\hline 180.01 MS Team Foundation Server 1 Yıllık Bakımı & & 200 \\
\hline
\end{tabular}

Yazılımın işler vaziyette olması için yapılan harcamalar varlığın maliyetine eklenmez ve gider olarak yazılır. Çünkü varlığın değerini arttırıcı veya varlığa değer katacak bir durum oluşmamaktadır. (Sumer ve Erer, 2010:37)

Örnek 3; 01.02.2015 tarihinde 3 numaralı varlık için İspanyolca yabancı dil yaması satın alınmıştır. Bedeli 1.000 TL’dir. 
Tablo 4: Örnek 3'ün Muhasebe Kaydı

\begin{tabular}{|l|r|r|}
\hline \multicolumn{1}{|c|}{ Hesap Adı } & Borç & Alacak \\
\hline $\mathbf{2 6 0}$ Haklar & 1.000 & \\
\hline 260.03 Crystal Report & 1.000 & \\
\hline 100 Kasa Hesabı & & 1.000 \\
\hline
\end{tabular}

illk işlerliğin ardından varlığın değerinde artış yapacak olan yukarıdaki işlem için harcanan tutar, varlığın maliyetine eklenerek aktifleştirilir. Ancak rutin işlerden olan bakım harcamaları giderleştirilir.

Örnek 4; 01.03.2015 tarihinde 1 numaralı yazılım için versiyon değişikliğine gidileceği yönetim kurulunda kararlaştırılmıştır. Visual Studio 2015, 5.000 TL'ye 1 yıl kullanım hakkı ile peşin olarak satın alınmıştır.

Tablo 5: Örnek 4'ün Muhasebe Kaydı

\begin{tabular}{|l|r|r|}
\hline \multicolumn{1}{|c|}{ Hesap Adı } & Borç & Alacak \\
\hline 260 Haklar & $\mathbf{5 . 0 0 0}$ & \\
\hline 260.05 Visual Studio 2015 & 5.000 & \\
\hline 268 Birikmiş Amortisman & 500 & \\
\hline 268.01 Visual Studio 2013 & 500 & \\
\hline 689 Diğer Olağan dışı Gider ve Zararlar & $\mathbf{2 . 5 0 0}$ \\
\hline 100 Kasa Hesabı & $\mathbf{3 . 0 0 0}$ \\
\hline 260 Haklar & $\mathbf{5 . 0 0 0}$ \\
\hline 260.01 Visual Studio 2013 & 5.000 \\
\hline
\end{tabular}

Yönetim kurulu kararı ile yeni bir yazılım alımı sonucu bir öncekinin kullanılmayacak olması durumunda yazılımın defter değeri zarar olarak yazılması gerekmektedir. (Yazılımın aylık itfa payı 250 TL idi.) (TMS-16, 67) Böylece bilanço dışına çıkartılır. Yeni alınan yazııım bilançoya eklenir. (Çankır, 2010)

Yazılımın ilk muhasebe kaydı ve sonrasında gerçekleşebilecek harcamalara yönelik verilen örneklerin özeti aşağıdaki tablodadır.

Tablo 6: Aktifleştirilecek ve Giderleştirilecek Yazılım Harcamaları

\begin{tabular}{|l|c|c|}
\hline Harcama Konuları & Aktifleştirilir & Giderleştirilir \\
\hline Satın Alma Fiyatı & $\mathrm{V}$ & $\mathrm{X}$ \\
\hline Kullanıma hazır hale getirmeye yönelik harcamalar & $\mathrm{V}$ & $\mathrm{X}$ \\
\hline Değerini arttırıcı harcamalar & $\mathrm{V}$ & $\mathrm{V}$ \\
\hline İşlerliğinin sürdürülmesine yönelik harcamalar & $\begin{array}{c}\text { Yenisinin elde } \\
\text { etme bedeli }\end{array}$ & $\begin{array}{c}\text { Eskisinin defter } \\
\text { değeri }\end{array}$ \\
\hline Öncekinin İtfa süresi bitmeden yeni versiyona geçilmesi
\end{tabular}




\section{FAYDALI ÖMÜR VE AMORTISMAN}

Satın alınan yazılımların ilk kayıtlarından sonra bu varlıkların itfa paylarının hesaplanması ve ilgili hesaplara kayıt edilmesi gerekmektedir. Bu konuda TMS 38 standardı iki kavramdan bahsetmektedir. Bunlar şunlardır:

1) Sınırlı Faydalı Ömür: Varlığın işletmeye olan faydasının önceden belirlenebilen biçimde olduğu durumlardır.

2) Sınırsız Faydalı Ömür: Varlığın işletmeye olan faydasının ne zaman biteceğinin belirlenemediği durumlardır.

Bir maddi olmayan duran varlığın muhasebeleştirilmesinde yararlı ömrü dikkate alınır. Sınırlı bir yararlı ömre sahip bir maddi olmayan duran varlık itfaya tabi iken, sınırsız yararlı ömürlü bir maddi olmayan duran varlık itfaya tabi olmaz. (TMS-38, 89)

Hükmü gereğince sınırlı yararlı ömrün nasıl belirleneceği, neyin temel alınması gerektiği sorusunu doğurmaktadır. Standardın 90 a ve g ifadeleri oldukça somut temellerden bahsetmektedir. "Varlığın işletme tarafından beklenilen kullanım süresi ve başka bir yönetim ekibi tarafından etkin olarak kullanılıp kullanılamayacağı" ve "Varlık üzerindeki kontrol süresi ve varlığın kullanımı ile ilgili, buna ilişkin kiralamaların bitiş tarihi gibi, yasal ve benzeri sınırlamalar" ifadelerinde varlığın kullanım süresini teşkil eden lisans sözleşmesindeki yasal haktan bahsetmektedir. Yani lisans sözleşmesi kaç yıllık yapılırsa satın alınan yazılımın faydalı ömrünün de o kadar olması gerekmektedir.

26752 sayılı Resmi Gazetede yayınlanan Genel Yönetim Muhasebe Yönetmeliği Genel Tebliği'nin (Resmi-Gazete, www.resmigazete.gov.tr, 2008) ekine göre kamu idarelerinde uygulanacak muhasebe sistemlerinde 260-Haklar Hesabında kayıtlı duran varlıklara ilişkin olarak:

1) Amortisman oranı \%100 olarak belirlenmiştir.

2) Yıl içerisinde yapılan değer artırıcı harcamalar varlığın maliyet bedeline eklenecek ve yılsonunda aynı şekilde amortismana tabi tutulacaktır. Bu varlıklar için daha sonraki yıllarda yapılan harcamaların tamamı doğrudan giderleştirilecektir.

ifadelerinden de anlaşılacağı üzere Maliye Bakanlığı, kamu idarelerinde yazılımların faydalı ömrünün 1 yıl olduğunu belirlemiştir.

333 sıra no'lu VUK Genel Tebliği (Resmi-Gazete, 2004) ekli listedeki açıklamaya göre "4.3 Bilgisayar yazılımları" sınıflandırması uyarınca 3 yılda ve $\% 33,3$ amortisman oranı ile itfa edilmesi istenmektedir.

Kamu ve özel sektörün yazılımların faydalı ömür açısından tabi oldukları miktarlar Maliye Bakanlığı'nca değişik olsa da faydalı ömrün fazla olamayacağı açıktır. TMS-38 92. maddesinde "Teknolojide meydana gelen hızlı değişimler nedeniyle, bilgisayar yazılımları ve diğer birçok maddi olmayan duran varlık teknolojik açıdan eskime tehdidi altındadır. $\mathrm{Bu}$ nedenle, yararlı ömürleri genellikle kısa olacaktır." ifadesi yer almaktadır. Buradan da anlaşılacağı üzere satın alınan yazılımların faydalı ömürlerinin çok fazla olamayacağı gerekçelendirilmiştir. TMS'ye göre raporlama yapılacak olduğunda lisans sözleşmesinin geçerlilik süresinin temel alınması en somut adım olacaktır. Tabi bu durum sabit bir süre 
ortaya koymamaktadır. Yani her yazılımın kullanım hakkı farklı sürelerden olabilir ve bunun üzerinden itfa edilebilir.

Tablo 7: Yazılımların Sınırlı Ömür Süreleri

\begin{tabular}{|l|c|}
\hline & İtfa Süreleri \\
\hline Kamu İdarelerinde & 1 yıl \\
\hline Özel Sektörde (VUK) & 3 yıl \\
\hline TMS 38'e göre & Sözleşme süresine göre \\
\hline
\end{tabular}

Sınırlı yararlı ömürlü maddi olmayan varlıkların itfa yöntemleri standardın 98. maddesinde belirtildiğine göre doğrusal, azalan bakiyeler ve üretim birimi yöntemlerinden biri olabilir. Bu yöntemlerden hangisinin seçileceği konusunda, varlığın tahmini olarak gelecekte yaratacağı ekonomik faydanın durumuna göre belirlenmesi esasına dayanmalıdır.

1 yıllık kullanım hakkı sağlayan sözleşmeler ile yazılım satın alındıysa zaten yılsonunda varlığın tamamı giderleşecektir. Yöntem fark etmeyecektir. Ancak örneğimizdeki gibi yazııım üretmek için satın alınan diğer yazılımların itfa payları, üretim sürecindeki kullanımlarına göre dağıtılabilir. Bu yaklaşım da gerçeğe uygunluk ilkesine göre olmuş olur.

Örnek 5; Mevcut satın alınan yazılımların Ocak ayı sonundaki doğrusal yöntem benimsenerek, üretim ile ilişkilendirilmeyen biçimde itfa payları hesaplanıp, sunulmuştur. (Kullanım hakları 1 yıl idi.) (Maliyet / 12)

\section{Tablo 8: Örnek 5'in Muhasebe Kaydı}

\begin{tabular}{|l|r|r|}
\hline \multicolumn{1}{|c|}{ Hesap Adı } & Borç & Alacak \\
\hline 770 Genel Yönetim Giderleri & $\mathbf{1 . 8 3 3}$ & \\
\hline 770.01 Visual Studio 2013 & 250 & \\
\hline 770.02 MS SQL Server Standard Edition 2012 & 625 & \\
\hline 770.03 Crystal Report & 125 & \\
\hline 770.04 MS Team foundation server & 833 \\
\hline 268 Birikmiş Amortisman & $\mathbf{1 . 8 3 3}$ \\
\hline 268.01 Visual Studio 2013 & 250 \\
\hline 268.02 MS SQL Server Standard Edition 2012 & 625 \\
\hline 268.03 Crystal Report & & 125 \\
\hline 268.04 MS Team foundation server & 833 \\
\hline
\end{tabular}

Kullanılan yazılımların itfa paylarından üretim süreçleriyle eşleştirilebilen kısımlar 770 nolu hesaba kayıt edilmemelidir. Bunun yerine yeni oluşturulan varlığın maliyetine eklenmelidir. Yeni varlık, mevcut düzenlemeler çerçevesinde 263 Araştırma ve Geliştirme Giderleri hesabında takip edilmelidir.

Yazılım geliştirme sürecindeki tasarım, kodlama, test, devreye alma aşamalarında üretimle ilişkilendirilebilen yazılımların itfa payları yeni oluşturulan yazılımın maliyetine eklenir. (TMS-38, 66-d)

Bu konunun detayına inildiğinde yazılım geliştirme süreçlerinden tasarım aşaması bazı Amerikan Standartlarına göre geliştirme sayılmazken bazısında geliştirme sürecinden sayılmaktadır. (Putra, 2009) TMS 38'de net olarak bu ayrım belirtilmese de 66.madde 
içinde "yaratılması, üretilmesi, hazırlanması" ifadelerinden yaratılması kısmı tasarıma denk düşmektedir.

Tek düzen hesap planının TMS'nin tavsiye ettiği şekilde kayıtlar tutulabilmesi için bazı düzenlemelerin yapılması gerektiğine dair birçok eser kaleme alınmışken bu amaçla bizim de eklememiz şu şekildedir: Her şeyden önce araştırma giderleri aktifleştirilemez olduğundan 263 nolu hesabın adından bu ifadenin kaldırılması gerekmektedir. "Geliştirilen Varlık" başlığı altında geliştirilen yazılımın amacının (satış veya kullanım) belirtilerek kaydedilmesini sağlayan şekilde olması gerekmektedir. Örneğin; Satış Amaçlı Geliştirilen Varlıklar ve Kullanım Amaçlı Geliştirilen Varlıklar gibi.

Yazılım geliştirme sürecindeki bazı aşamaların harcamaları da araştırma kapsamına gireceğinden bu kategorideki itfa payları 750 Araştırma ve Geliştirme Giderleri Hesabına kayıt edilmelidir. Söz konusu aşamalar şunlardır: Yazılım geliştirme süreçleri arasında geçen "İsteklerin belirlenmesi ve Analiz" ile geliştirme sonrası ortaya çıkan "Bakım” süreçleridir.

Bu aşamada da önerimiz şu yöndedir. Geliştirme faaliyetleri gider yazılamayacağından hesabın isminin sadece "Araştırma Giderleri" olarak düzenlenmesidir. Bu şekilde düzenlemeler yapılırsa hesap isimleri ve işleyişleri ile ifadelerin kavramsal bütünlüğünün çelişmemesi sağlanmış olacaktır.

TMS 38'in 100. maddesinde kalıntı değerden bahsedilmektedir. Amortisman hesaplaması yapılırken varlığın maliyetinden kalıntı değerinin çıkarılarak kalan bakiye üzerinden itfa edilmesi gerekmektedir. Ancak dışarıdan satın alınan ve kullanım süresi sınırlı olan bu tür varlıkların satışı ile el değiştirmesi mümkün olmamaktadır. Çünkü işletme, 3. kişilere yazılımın kullanım yetkisini verme, şifre üretme gibi bir güce sahip değildir. Dolayısı ile yasal olarak 3. kişilere satışı mümkün değildir.

Kalıntı değer ancak şu durumda ortaya çıkabilir: yazılım satın alma sözleşmesinde kullanım süresinin uzatılmasında belirli bir oranda indirim uygulanır; gibi bir ifade var ise yazılımın süre sonunda ne kadar ederi olduğu önceden bilinebilir. Böylece bulunan değer, itfa hesaplamasına dâhil edilerek muhasebeleştirilmelidir.

Yukarıdaki örnekte işletmenin kullanmış olduğu yazılımların üretimle ilişkilendirilmediği senaryoya göre anlatım yapılmıştı.

Örnek 6; aynı değerleri kullanarak Ocak ayında bunların bir kısmının geliştirme bir kısmının araştırma ve bir kısmının da üretimle ilişkisi olmayacak şekilde kayıt edilmesine örnek verelim. 
Tablo 9: Örnek 6'nın Muhasebe Kaydı

\begin{tabular}{|l|r|r|}
\hline \multicolumn{1}{|c|}{ Hesap Adı } & \multicolumn{1}{c|}{ Borç } & \multicolumn{1}{c|}{ Alacak } \\
\hline 263 Araştırma ve Geliştirme Giderleri & $\mathbf{9 1 7}$ & \\
\hline 263.01 Öğrenci İşleri Yazılımı (Satış Amaçı) & 917 & \\
\hline 750 Araştırma ve Geliştirme Giderleri & $\mathbf{4 5 8}$ & \\
\hline 750.01Öğrenci Işleri Yazılımı (Satış Amaçlı) & $\mathbf{4 5 8}$ & \\
\hline 770 Genel Yönetim Giderleri & 63 & \\
\hline 770.01 Visual Studio 2013 & 156 & \\
\hline 770.02 MS SQL Server Standard Edition 2012 & 31 & \\
\hline 770.03 Crystal Report & 208 & \\
\hline 770.04 MS Team foundation server & & \\
\hline 268 Birikmiş Amortisman & & \\
\hline 268.01 Visual Studio 2013 & & \\
\hline 268.02 MS SQL Server Standard Edition 2012 & & \\
\hline 268.03 Crystal Report & 1.833 \\
\hline 268.04 MS Team foundation server & & \\
\hline
\end{tabular}

Yukarıdaki örnekte 1 aylık ayrılması gereken itfa paylarının işletme faaliyetlerine göre hangi süreçte yazılımların ne kadar kullanılarak zaman geçirdiği esasına göre ayrıştırılmıştır. TMS38 'in 57. maddesindeki geliştirme safhasına ait işlemlerin gerçekleştiği kabul edilmiş ve yazılımların oransal olarak kullanımı, \%50 geliştirme, \%25 Araştırma ve \%25 Üretimle ilgisi olmayan faaliyetlerde bulunulduğu varsayılmıştır. (Saban ve Genç, 2005:128)

Yukarıdaki varsayımdaki gibi kullanılan yazılımların hangi işlerde ne kadar süre ile çalıştırıldıkları tespit edilebiliyorsa yukarıdaki gibi ayrıştırarak muhasebeleştirmek en doğrusudur.

Yazılımların süreç takibini yapabilecek başka yazılımlar günümüzde "Proje Yönetim Araçları" genel adı ile piyasada satılmaktadır. Bu yazılımlar, birçok projenin süreçlerinin rahatlıkla takip edilebildiği ve proje yöneticisinin işini kolaylaştıran, çok çeşitli süreç raporları üretebilen yazılımlardır. En iyi yaptıkları işler arasında projenin zaman, iş gücü ve kaynak planlamalarını yapmalarıdır. Bu üç kritik öğenin birbiriyle ilişkisini gant şemaları ile raporlamak ve istendiğinde maliyet raporlarını çıkarabilmektedirler. Yazılım üretmek için kullanılan diğer yazılımlar da kaynak olduğundan yapılacak işler ile süreçlerde geçecek süreler bu tür proje yönetim araçları kullanılarak takip edilebilir ve raporlar üretilebilir. Örnek vermek gerekirse piyasada en çok bilinen proje yönetim aracı "Microsoft Project" tir. Türkiye Muhasebe Standartları gerçeğe uygun raporlama istediğinden yazılımlar ile üretim yapan işletmelerin araştırma ve geliştirme safhalarını birbirinden ayırarak muhasebe kayıtlarını tutmaları gerekmektedir. 
Tablo 10: Yazılım üretiminde kullanılan yazılımların itfa paylarının iş süreçlerine göre sınıflandırılması ve TMS 38'in muhasebe yaklaşımı

\begin{tabular}{|l|c|l|}
\hline Süreç & TMS $\mathbf{3 8}$ Yaklaşımı & Süreçlere denk gelen yazılım üretim aşamaları \\
\hline Araştırma & Giderleştirme & İsteklerin belirlenmesi, Analiz \\
\hline Geliştirme & Aktifleştirme & Tasarım, Kodlama, Test, Devreye alma \\
\hline Sınıflandırılamayan & Giderleştirme & \\
\hline
\end{tabular}

Sınırsız yararlı ömrü olan maddi olmayan duran varlıklar için itfa payı hesaplanamaz ve hesaplanmaz. (TMS-38, 107) Kendi kullanımı için yazılım geliştiren firmalar ürettikleri yazılımdan gelecekte ne zamana kadar fayda göreceklerini tahmin edemeyebilirler. Bu durumda aktifteki varlıklarını amorti edemezler. Her yılsonunda varlığın faydasında bir sınırılık söz konusu mu? diye gözden geçirmek gereklidir. Makul gerekçelerle sınırlılık söz konusu ise o seneden itibaren itfa payları hesaplanarak giderleştirilmeye başlanabilir. Herhangi bir sınırlılık durumu oluşmadan veya sınırlılık durumu başlamışken ancak tamamının amorti edilmediği durumda yazııımın tüm haklarıyla satılması veya yönetimin karar vererek artık kullanılmayacak yönünde karar vermesi durumlarında varlığın defter değerinin tamamı giderleştirilir.

\section{YENIDEN DEĞERLEME}

Teknolojinin gelişimi, ihtiyaçların çeşitlenmesi, pazarlama teknikleri gibi nedenlerle yazılımlar devamlı olarak yeni versiyonlar şeklinde piyasa sürülmektedir. Dolayısı ile ürünlerin yaşam döngüleri kısa olmaktadır. Yeniden değerleme yapabilmek için ürünün aktif bir piyasasının olması gerekmektedir. Hala alınıp satılması gerekmektedir. Bu şart da sağlanıyorsa ürünün defter değeri ile piyasa değeri arasındaki farka bakılır. Bu kontrol her sene sonunda yapılabilir.

Satın alınan yazılımların faydalı ömürlerinin kullanım sözleşmesinin bitişi ile sonlanıyor olması ve çoğu satış sözleşmesinin süresi 1 yıl ile sınırlı olması zaten yeniden değerleme yapmaya imkân vermemektedir.

Ancak sözleşme süresi daha uzun olan durumlarda yeniden değerleme yapmak gerekebilir. Yine de itfa etme süresi bitmeden yeniden değerleme işlemine tabi olacak kadar değer değişikliğine uğraması oldukça zor bir durumdur. Şayet bu şart sağlanmışsa genelde değer düşüklüğünden bahsedilebilir. Değer artışından bahsetmek ise satın alınan yazılımlar için üzerine yeni ürünlerin gelmesinden dolayı mümkün olmayacaktır. 
Şekil 1: Maddi Olan / Olmayan Varlıkların Yeniden Değerleme Modeli

(Akbulut ve Marşap, 2006:92)

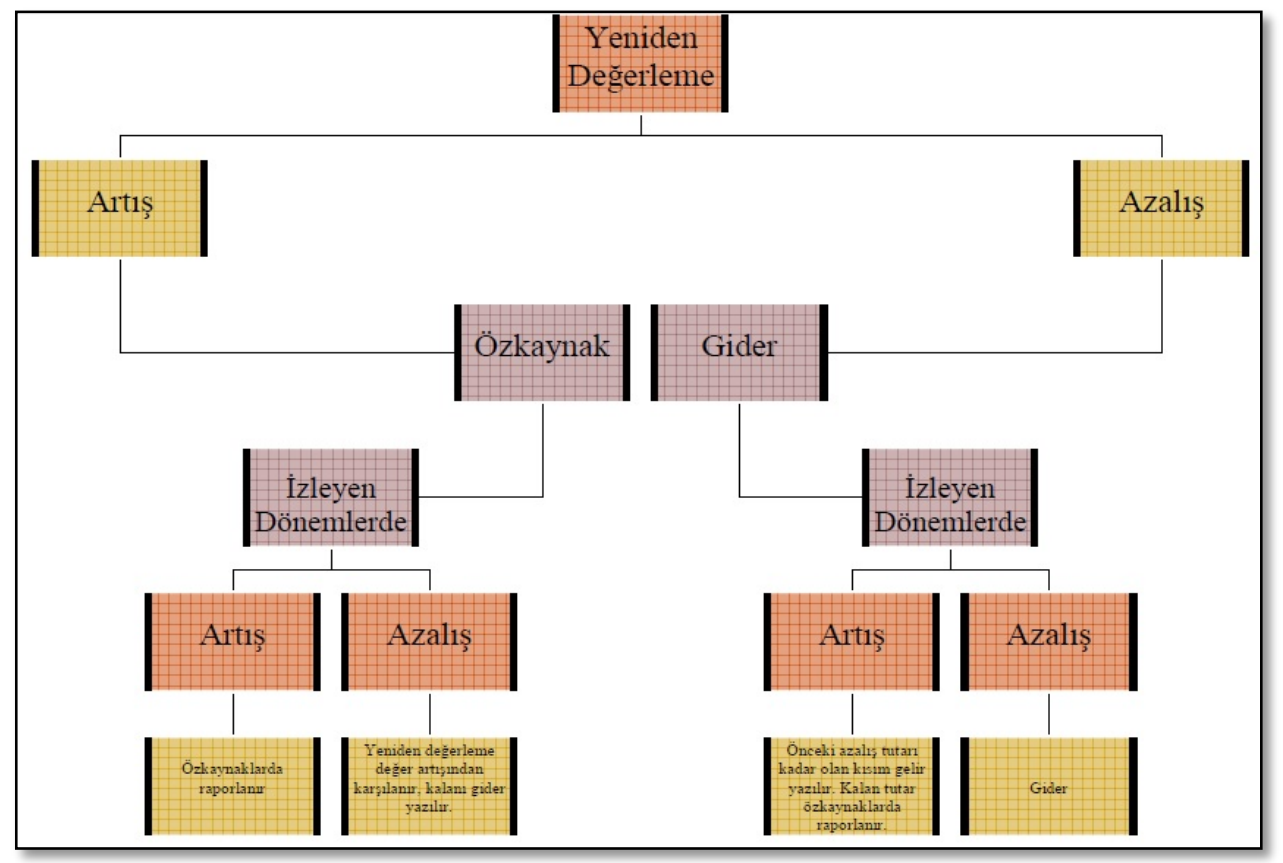

Maddi olmayan duran varlıklar, ilk muhasebeleştirmenin ardından, muhasebe politikası olarak "maliyet modeli" ve "yeniden değerleme modeli" seçeneklerinden birisini seçerek değerlemeye tabi tutulur. (TMS-38, 72) Yeniden değerleme modeli uygulandığı takdirde; maddi olmayan duran varlığın değerinde değer artışı varsa, bu artış öz kaynaklar grubunda, diğer kapsamlı gelir unsuru olarak yeniden değerleme fazlası adı altında muhasebeleştirilir. Eğer, değer azalışı söz konusu olursa, bu azalma gider olarak kayıtlara alınır. (TMS-38, 8586)

Daha önceki dönemde değer azalışı olmuş bir maddi olmayan duran varlığın yeniden değerleme sonucu değerinde artış olmuşsa, önceki dönemde kar veya zararda muhasebeleştirilen yeniden değerleme azalışı kadar kar veya zarar, kalan kısmı diğer kapsamlı gelir olarak muhasebeleştirilir. (Gökgöz, 2013:27) Aksi durumda, daha önceki dönemlerde değer artısı olmuş bir maddi olmayan duran varlığın yeniden değerleme sonucunda değer azalmışsa, önceki dönemlerdeki diğer kapsamlı gelirde muhasebeleştirilen yeniden değerleme artışı ile içinde bulunulan dönemdeki değer azalışına karşılık mahsup edilir. Değer azalışından kalan tutar olursa gider yazılarak kar veya zarar arasında muhasebeleştirilir. (TMS-38, 85-86)

Özetle, şekil 1'deki maddi duran varlıkların yeniden değerlemesi ile ilgili hiyerarşi maddi olmayan duran varlıklar için de geçerlidir.

İlk değerlemede değer artışı söz konusu olduğunda 522 M.D.V. Yeniden Değerleme Artışları hesabının "Alacak" tarafına yazılır. Illerleyen dönemlerde değer azalışı olursa önce bu hesap sıfırlanıncaya kadar "Borç" yazılır. Hala daha değer düşüklüğü var ise 654 Karşılık 
Giderleri hesabının borcuna yazılmalıdır. (Sarıay, 2012:8) ilk değerlemede değer düşüklüğü varsa, önce 654 Karşılık Giderleri hesabı borçlandırılır, gelecek dönemlerde bir değer artışı söz konusu olursa (654'teki bakiye aşılıncaya kadar) 644 Konusu Kalmayan Karşılıklar hesabının alacak tarafına yazılır. Daha sonra 522 numaralı hesabın alacak tarafına yazılır. (Fırat, 2008:138) Değer artışı ve azalışlarında birikmiş amortisman ve varlığın hesabı ilgili oranla genişletilir veya daraltılır.

\section{SONUÇ}

Yazılımların muhasebeleştirilmesi konusunda yazılımın işletme açısından ne amaçla kullanıldığı önemlidir. İşletmenin yazılımı hangi amaçla kullandığına göre muhasebeleştirmede yön verecek olan standartlar değişebilmektedir. Kullanım amaçları arasında satın alarak faydalanmak, yazılımı kendi kullanımı için işletme içinde üreterek faydalanması ve satmak için işletme içinde üretmek gibi durumlar bulunmaktadır.

Satın alınan yazılımların muhasebeleştirilmesi için TMS-38 standardı gerekli hükümleri açıkça belirtmektedir. Ancak diğer amaçlar için yazılımların muhasebeleştirilmesi sadece TMS 38'e göre yapılmamaktadır.

Satın alınan yazılımın maliyetinin belirlenmesi için yazılımın işler hale gelinceye kadar gerekli harcamaların tamamı olarak özetlemek mümkündür. Böylece yazılım ilk kez 260 no'lu hesapta kayıt altına alınır. Bundan sonraki süreçte yazılımın değerini arttırıcı durumlar için harcamalar yapılırsa bunlar da yazılımın maliyetine eklenir, yani aktifleştirilir. Ancak yazılımın normal şekilde işlemesi için yapılan bakımların harcamaları gider olarak kayıt edilmelidir.

Yazılımların amortismanı konusunda yararlı ömürlerinin nasıl tanımlandığı konusu önemlidir. Standartta belirtilen şekilde sınırlı ve sınırsız yararlı ömür tanımları bulunmaktadır. Sınırsız yararlı ömürlü olan yazılımlar için amortisman ayrılmaz iken, sınırlı yararlı ömürlü olan yazılımlar için doğrusal, azalan bakiyeler ve üretim birimi yöntemlerinden biri seçilerek faydalı ömür üzerinden amorti edilir. Satın alınan yazılımların faydalı ömrünün belirlenmesi sözleşmede geçen yıl miktarı ile sınırlandırılmış kabul edilir.

Satın alınan yazılımın itfa payının hangi hesaplarda muhasebeleştirileceği konusunda karar verebilmek için yazılımın faydasının işletmenin üretim konusu ile ilişkisi açısından incelenmesi gerekmektedir. Eğer üretim ile ilişkilendirilemiyorsa 770 no'lu hesap kullanılmalıdır. Üretim ile ilişkilendirilebiliyorsa bu kez de Araştırma faaliyetleri mi? Geliştirme faaliyetleri mi? olduğunun tespiti gerekmektedir. Araştırma faaliyetlerine isabet eden kısımlar 750 no'lu hesabın borcuna, Geliştirme faaliyetlerine isabet eden kısımlar da 263 no'lu hesabın borcuna kayıt edilmelidir. Alacaklı olarak çalışacak hesap daima 268 no'lu hesap olacaktır.

Tek düzen hesap planında bulunan mevcut hesap isimlerinin TMS standartlarına uyumu açısından bazı hesap isimleri önerilmiştir. Bunu destekler şekilde TMS-38 126. maddesinde işletme, araştırma ve geliştirme giderlerini kamuoyuna açıklamakla sorumlu tutulmaktadır. 
Yeniden değerleme konusunda yazılımların ömürlerinin kısa olmasından dolayı satın alınan yazılımların itfa süreleri içinde değerleme yapacak kadar anlamlı bir farkın oluşması oldukça düşük olsa da maddi olan duran varlıkların değerleme kriterleri ile aynıdır. Hangi şart (değer artışı veya azalışı) sağlanıyorsa maddi duran varlıklar gibi muhasebeleştirilebilir.

\section{KAYNAKÇA}

Akbulut ve Marşap, Y. M. (2006). Maddi Duran Varlıklarda Değer Düşüklüğünün "TMS 36: Varlıklarda Değer Düşüklüğü" Standardı Kapsamında İncelenmesi ve IMKB'de İşlem Gören Şirketlerdeki Uygulamaların Değerlendirilmesi. Muhasebe Bilim Dünyası Dergisi, 8(4), s.92.

Arpacı, M. C. (2010). Türkiye'de Yazılım Sektöründe Sağlanan Teşvikler ve Maliyetleme: Türkiye ve Hindistan Karşılaştırılması. Ankara: Gazi Üniversitesi, Sosyal Bilimler Estitüsü, İşletme Anabilim Dalı, s.4

Britannica, E. (2014). Britannica Academic Edition. http://www.britannica.com/EBchecked/topic/713766/JohnWilder-Tukey/

Çankır, B. (2010). Sabit Kıymetlerin Kayıtlardan Çıkarılmasında Özellikli Durumlar. E-Yaklaşım (208). http://www.burhaneray.com/Sabit-Kiymetlerin-Kayitlardan-Cikarilmasinda-Ozellikli-Durumlar/731

Fırat, H. (2008). Maddi Duran Varlıklarda Değerleme Esaslarının TMS Ve VUK Açısından İncelenmesi. VI. Muhasebe Uygulamaları Ve Vergi Mevzuatı Sempozyumu. Antalya, ss.103-138

GiB. (2015). Gelirler İdaresi Başk. http://www.gib.gov.tr/fileadmin/mevzuatek/eski/muhsisteb1ekmuh5c.htm

Gökgöz, A. (2013). Diğer Kapsamlı Gelirler ve Muhasebeleştirilmesi. Muhasebe ve Finansman Dergisi(Ocak), s.27.

Putra, L. D. (2009, May). http://accounting-financial-tax.com/. http://accounting-financialtax.com/2009/05/capitalization-and-amortization-of-software-cost/

Resmi-Gazete. (2004, Nisan 28).

http://www.resmigazete.gov.tr/main.aspx?home=http://www.resmigazete.gov.tr/eskiler/2004/04/20040428.ht m\&main=http://www.resmigazete.gov.tr/eskiler/2004/04/20040428.htm

Resmi-Gazete. (2008, Ocak 10). http://www.resmigazete.gov.tr/eskiler/2008/01/20080110-6.htm

Saban ve Genç, M. v. (2005). Araştırma ve Geliştirme Faaliyetlerinin IAS-38 "Maddi Olmayan Duran Varlıklar" Kapsamında Muhasebeleştirilmesi. Mali Çözüm(70), ss.123-133.

Sarıay, í. (2012). Türkiye Muhasebe Standartlarına Göre Maddi Duran Varlıkların Değerlemesi. Electronic Journal of Vocational Colleges, s.8.

Sumer ve Erer, H. M. (2010). Yazılımların (TMS38'e Göre) Değerlemesi. Mali Çözüm, s.37.

Tavukçuoğlu, D. C. (2004). Bilişim Terimleri Sözlüğü. Ankara: Asil Yayın.

TMS-16. (67). Türkiye Muhasebe Standartları, Maddi Duran Varlıklar Standardı, www.kgk.gov.tr

TMS-38. (9). Türkiye Muhasebe Standartları, Maddi Olmayan Duran Varlıklar Standardı, www.kgk.gov.tr

TMS-38. (10).

TMS-38. (12).

TMS-38. (13).

TMS-38. (17).

TMS-38. (25-26).

TMS-38. (27-28).

TMS-38. (66-d). 
TMS-38. (72).

TMS-38. (85-86).

TMS-38. (89).

TMS-38. (107).

Türk Dil Kurumu:

http://www.tdk.gov.tr/index.php?option=com_bts\&arama=kelime\&guid=TDK.GTS.53aad67984ae14.80290016 